\title{
Efficacy of Autologous Bone Marrow Mononuclear Cell Transplantation Therapy for Type 2 Diabetes Mellitus: An Updated Meta-Analysis
}

\author{
Xue-Jun Guo · Feng-Ju Li · Yu-Zhuo He · Shu-Fang Hou • \\ Hong-Bin Zhu • Ying Cheng · Zhen Nan • Xiao-Yan Lin
}

Received: October 28, 2018 / Published online: February 6, 2019

(C) The Author(s) 2019

\section{ABSTRACT}

Introduction: Studies of the effects of stem cell therapy on type 2 diabetes mellitus (T2DM) have not reached consistent results. Our metaanalysis aimed to systematically evaluate the efficacy of autologous bone marrow-derived stem cells (ABM-MNCs) on T2DM.

Methods: We systematically searched PubMed, EMBASE, Web of Science, and the Cochrane Library for studies published between 1980 and May 2018. Two researchers screened the literature independently following the inclusion and exclusion criteria. Meta-analysis of the pooled standard mean difference (SMD) with 95\% confidence interval (CI) was calculated based on either a fixed- or random-effects model.

Results: We identified six studies with 206 participants investigating the effects of autologous bone marrow stem cell therapy on T2DM after screening 102 studies found after the initial search. According to the pooled estimates,

Enhanced Digital Features To view enhanced digital features for this article go to https://doi.org/10.6084/ m9.figshare.7624328.

X.-J. Guo - F.-J. Li · Y.-Z. He - S.-F. Hou · H.-B. Zhu •

Y. Cheng $\cdot$ Z. Nan $\cdot$ X.-Y. Lin $(\bowtie)$

Department of Hemopathology, Puyang City

Oilfield General Hospital, Puyang City, Henan,

People's Republic of China

e-mail: xiaoyanlin124@163.com compared with the control group, after 12-month follow-up the ABM-MNC therapy group had a lower level of HbA1c (MD, - 1.18; $95 \% \mathrm{CI},-1.40$ to 0.95$)$ and lower required insulin dose $(\mathrm{MD},-2.05$; $95 \% \mathrm{CI},-3.55$ to - 0.55). HbA1c decreased after ABM-MNC therapy compared with before (12 months: $\mathrm{MD}$, -1.22 ; $95 \%$ CI, -1.43 to -1.0$)$. We also observed a significant decrease in insulin requirement after 3-, 6-, 9-, and 12-month follow-up in the ABM-MNC group, respectively.

Conclusion: Autologous stem cell therapy showed a beneficial effect on T2DM.

Keywords: Autologous bone marrow-derived stem cell; Insulin sensitivity; Meta-analysis; Systematic review; Type 2 diabetes mellitus

\section{INTRODUCTION}

Type 2 diabetes mellitus (T2DM) has emerged as a global epidemic associated with high morbidity and mortality rates [1]. The development of T2DM is characterized by the progressive deterioration of glycosylated hemoglobin (HbA1c) and glycemic control, which can lead to multiple organ complications and is related to the gradual degeneration of islet $\beta$-cells [2]. The ultimate goal of T2DM treatment is to preserve the function of islets, reduce HbA1c values, manage the blood glucose, and minimize the occurrence of complications. The 
current $\beta$-cell therapy methods include pancreas, islet cell, and stem cell transplantation; however, the lack of donor resources and immune rejection limit the clinical application of pancreas and islet cell transplantations. Stem cell transplantation is the most promising option for T2DM treatment. Stem cells are primordial cells that self-renew and differentiate into other types of cells, avoiding both immune rejection and ethical problems, which makes autologous bone marrow stem cell transplantation an attractive option [3].

Experimental studies have shown that bone marrow stem cells can differentiate into islet-like cells, secrete insulin, and maintain normal blood glucose [4]. The evidence for the utility of autologous bone marrow stem cell transplantation for T2DM treatment remains controversial. Estrada et al. [3] observed that autologous bone marrow along with hyperbaric oxygen therapy (HBO) significantly decreased the fasting plasma glucose levels and insulin doses and increased fasting C-peptide levels after 12 months. Bhansali et al.'s [5] study reported a significant improvement of fasting and glucagon-stimulated C-peptide levels; however, insulin resistance did not change significantly. A previous meta-analysis in 2016 included seven studies involving 224 patients, investigating stem cell therapy on T2DM for 6 months, and suggested that HbA1c and C-peptide levels were significantly reduced compared with baseline levels [6]. Another meta-analysis published in 2015 including 15 trials, and 497 patients showed a significant decrease in the daily insulin requirement at 3, 6, 9, and 12 months [7], but the FPG and C-peptide values did not change significantly. However, the previously published studies included some limitations such as limited numbers of trials or limited trials in the subgroup analysis, inclusion of participants with varying degrees of glycemic control at baseline, or relatively small sample sizes. Furthermore, new studies have been published since the latest meta-analysis that allow more detailed analysis of the effects in the subgroups.

Therefore, our study aims to critically evaluate the safety and efficiency of ABM-MNC transplantation on T2DM by using an updated meta-analysis. We hypothesized that ABM-
MNC transplantation could improve the T2DM biomarkers.

\section{METHODS}

\section{Data Sources and Search Strategy}

Two authors searched the PubMed, EMBASE, Web of Science, and the Cochrane Library databases up to May 2018 for eligible studies, and the senior author was consulted when there were discrepancies. The report was performed according to the Preferred Reporting Items for Systematic Reviews and Meta-Analysis (PRISMA) Statement [8]. Search terms included 'autologous bone marrow-derived mononuclear cell' OR 'autologous bone marrow mononuclear cell' OR 'autologous bone marrow derived hematopoietic stem cell' OR 'autologous bone marrow-derived stem cell,' OR 'autologous bone marrow-derived stem cell' and 'type 2 diabetes mellitus' OR 'T2DM.' Manual searches of reference lists and relevant narrative reviews were also performed. The search was limited to English-language papers and humans. In addition, 'type 2 diabetes' was also used as a search term; however, no additional studies were found. Gray literature and unpublished studies were not included. The complete search strategy is shown in Fig. 1. This article is based on previously conducted studies and does not contain any studies with human participants or animals performed by any of the authors.

\section{Selection Criteria}

Inclusion criteria were: (1) eligible original studies with a minimum follow-up period of at least 6 months after the initiation of therapy [6]; (2) ABM-MNCs as an independent intervention measure; (3) $n>5$. Exclusion criteria were: (1) insufficient information concerning evaluation rates; (2) animal trials; (3) studies designed as review articles, case reports, editorials, conference abstracts, and letters. When multiple articles were published with the same subjects and/ or study designs, we chose the studies with either a larger sample size or longer follow-up 


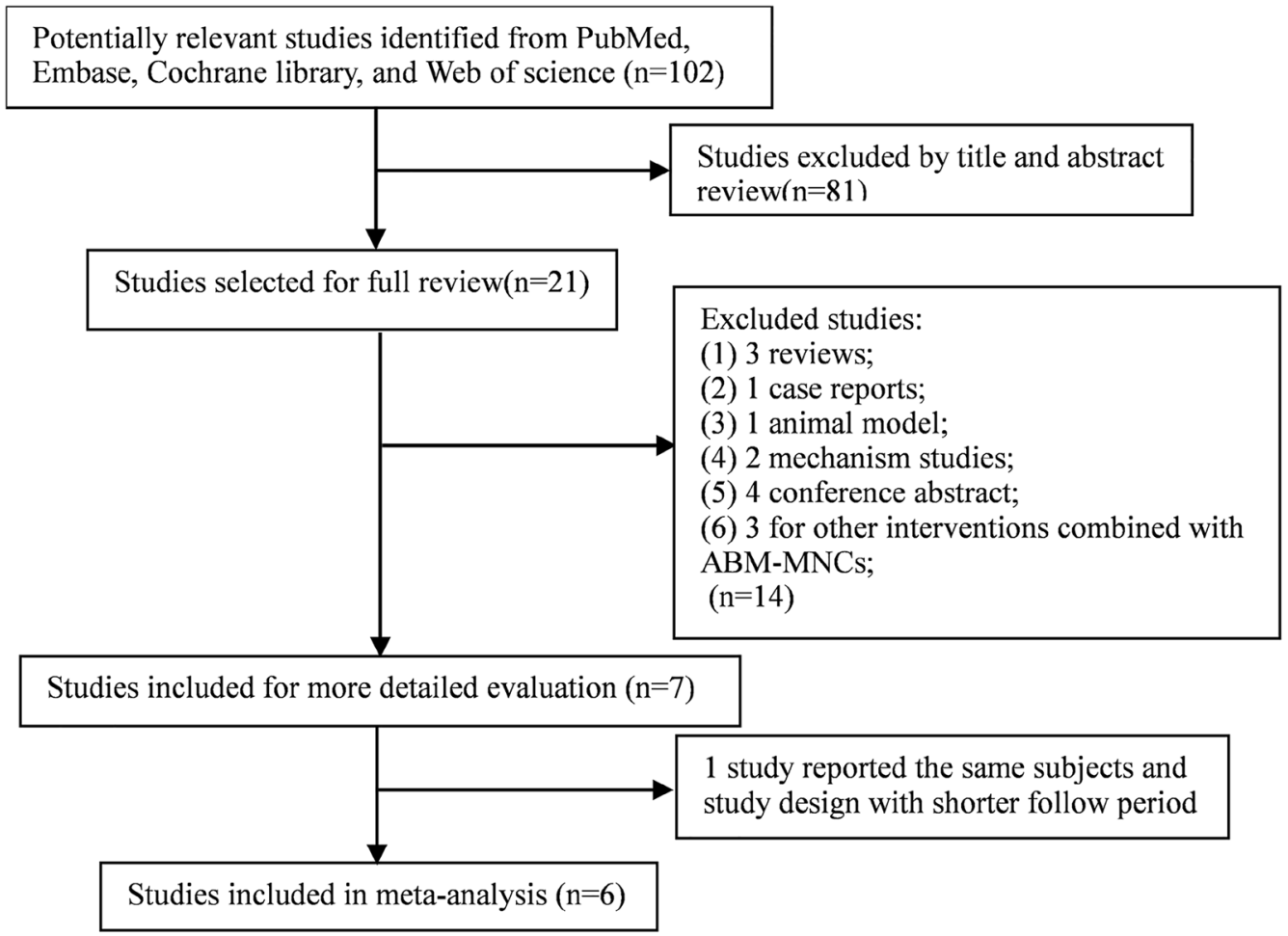

Fig. 1 Flow diagram of the literature search

period. Each trial was only represented once in our study to avoid putting more weight on certain trials.

\section{Data Extraction}

A standard data extraction form was used by two authors independently according to a standard Cochrane protocol to collect information including the following: the first author, study characteristics (i.e., year of publication, country), participant characteristics (i.e., mean age, sex, sample size, and mean history of T2DM), regimen used, measured outcomes [i.e., HbA1c, C-peptide, glucagon-stimulated C-peptide, fasting plasma glucose (FPG), patients' insulin requirements]. Whenever necessary, standard deviations were calculated from standard errors or confidence intervals. Change from baseline standard deviation was imputed using a correlation coefficient method referenced in the Cochrane Handbook for Systematic Reviews of Interventions. A third author was consulted when there were discrepancies about the study inclusion [9].

\section{Statistical Analysis}

The weighted mean difference (WMD) was used to compare continuous variables. Results reported in median and interquartile range were converted to mean and standard deviation (SD) $[10,11]$. Summary mean estimates with the corresponding SDs were derived by the method of DerSimonian and Laird using a random effects model [12]. A two-tailed value of $P<0.05$ was considered statistically significant. Furthermore, through calculating $\chi^{2}$ and $I^{2}$ statistical tests, we evaluated heterogeneity among the outcomes of the included studies. When effects were observed to be heterogeneous $\left(I^{2}>50 \%\right.$ and $\left.P<0.10\right)$, we used random-effects models [12]; otherwise, data were assessed using the fixed-effects model. RevMan 5.0 software was used to perform the meta-analysis. 


\section{RESULTS}

\section{Search Results}

The electronic search yielded 102 studies for evaluation. After title and abstract review, 81 published articles were excluded. After the fulltext screening, four studies were excluded because of the review or case-study design; three were excluded because they were non-human studies and four because they were conference abstracts. We also excluded three studies because the primary interventions were not ABM-MNCs. Two studies reported the same subjects and study designs; therefore, we excluded the studies with shorter follow-up periods. Details of the study selection process are shown in Fig. 1. Finally, six studies reporting ABM-MNC therapy for T2DM with a total of 114 patients were included in the meta-analysis through a strict screening process [13-17].

\section{Characteristics of Included Studies}

The clinical data of the included studies are summarized in Table 1 ; these were published from 2012 to 2017, with the sample sizes ranging from 7 to 118 . Of these six studies, four were conducted in India and two in China. Intervention regimens included ABM-MNCs and ABM-MNC HOT. The dose of injected cells ranged from $382.6 \times 10^{7}$ to $2.8 \pm 1.9 \times 10^{9}$, and the follow-up duration ranged from 6 to 36 months.

\section{Effects of Stem Cell Therapy on HbA1c}

Although the levels of HbA1c were available in all six trials [13-18], only three trials [13-15] were intentionally designed to enroll patients with $\mathrm{HbA} 1 \mathrm{c} \leq 7.5 \%$ to mitigate the effect of glucotoxicity on $\beta$-cell function and insulin sensitivity. Therefore, we only analyzed three of the HbA1c trials [16-18]. We observed that an ABM-MNC therapy group was statistically associated with a decreased level of HbA1c compared with the control group after 12 months (MD, -1.18 ; 95\% CI, -1.40 to $0.95 ; P<0.001$; Fig. 2). The estimated pooled MD showed a modest decrease of HbA1c after 12-month follow-up in the ABM-MNC therapy group compared with baseline (MD, - 1.22; 95\% CI, -1.43 to $-1.01 ; P<0.001$; Fig. 3 ).

\section{Effects of Stem Cell Therapy on FPG}

Information on FPG was available in six trials [13-18]. No statistically significant differences were observed between the ABM-MNC group and control group after 12-month follow-up (SMD, $-0.30 ; 95 \% \mathrm{CI},-1.36$ to $0.75 ; P=0.57$; Fig. 4). The random-effects analysis was adopted owing to the heterogeneity among studies $\left(I^{2}=80 \% ; P<0.10\right)$. Similarly, there were no statistically significant differences in FPG after 3-, 6-, 9-, and 12-month follow-up in the ABMMNC group, respectively (Table 2 ).

\section{Effects of Stem Cell Therapy on Fasting C-peptide Levels}

Three trials $[13,14,16]$ studied fasting C-peptide levels. Two studies showed that there was no significant difference between the ABMMNC group and control group after 12-month follow-up (SMD, 1.05; 95\% CI, -0.72 to 2.82; $P=0.24$; Fig. 5). The estimated pooled MD showed an increase of fasting C-peptide after 12-month follow-up in the ABM-MNC therapy group (SMD, 0.99; 95\% CI, 0.15 to 1.84 ; $P=0.02$; Table 3 ), but the observed increasing results were not found at the 3- and 6-month follow-up, respectively (Table 3 ).

\section{Effects of Stem Cell Therapy on Glucagon- stimulated C-peptide Levels}

Information on glucagon-stimulated C-peptide was available in four trials involving 58 patients $[13-15,18]$. Two studies showed that there was no significant difference between the ABM-MNC group and control group after 12-month followup (SMD, $0.63 ; 95 \% \mathrm{CI},-0.01$ to $1.28 ; P=0.06$; Fig. 6). In accordance with the fasting C-peptide level, the estimated pooled SMD showed an increase of glucagon-stimulated C-peptide after 12-month follow-up in the ABM-MNC therapy group (SMD, $0.91 ; 95 \% \mathrm{CI}, 0.38$ to 1.44 ; 


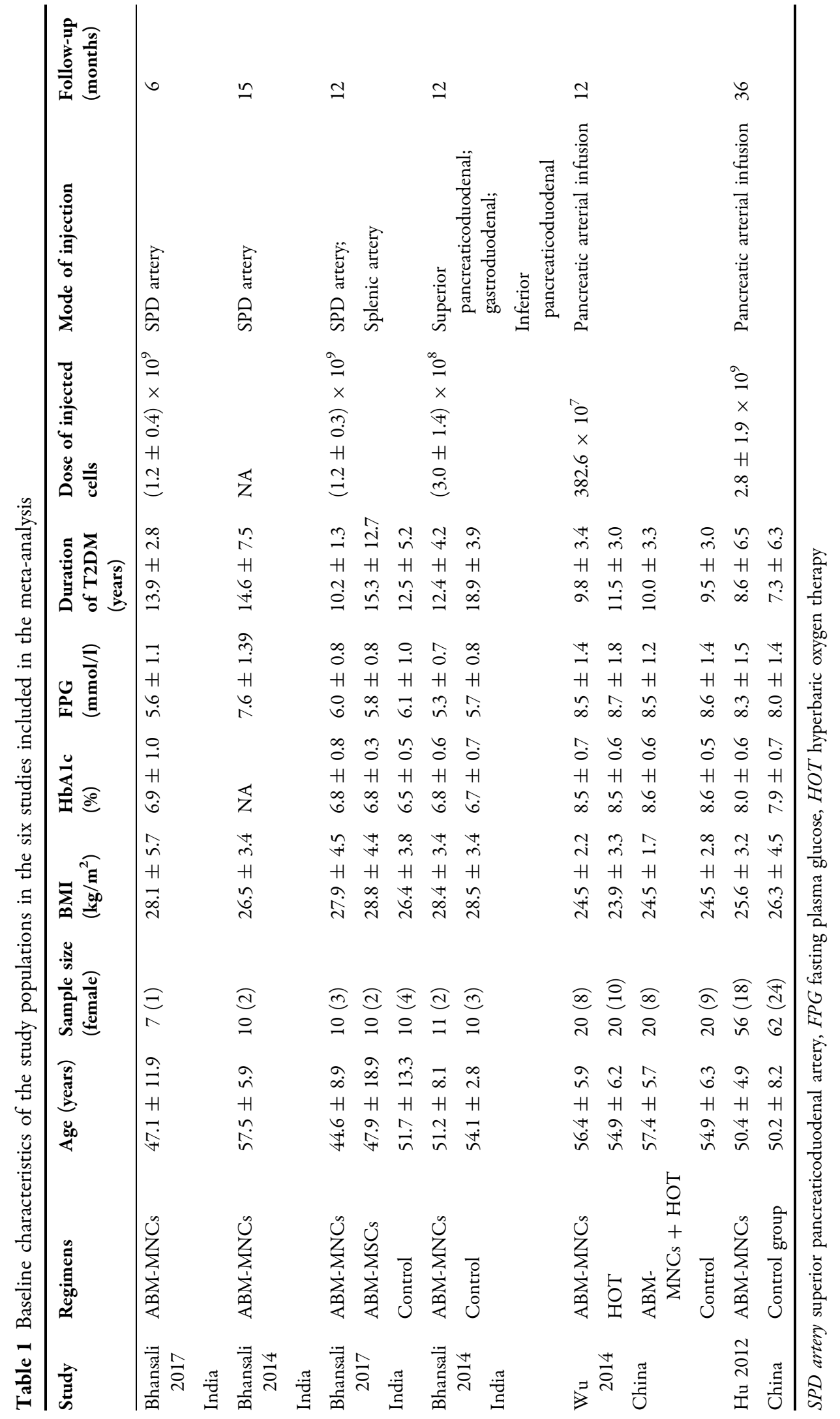




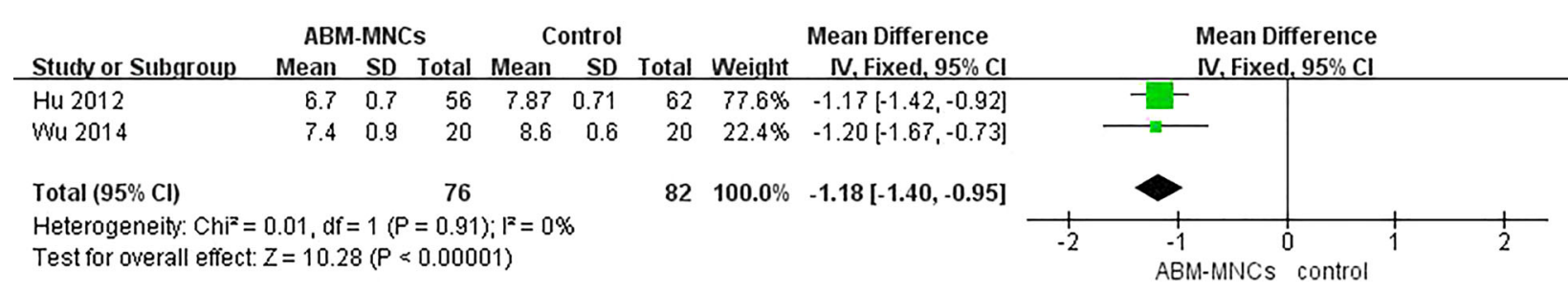

Fig. $2 \mathrm{HbAlc}$ changes between the ABM-MNC therapy and control group

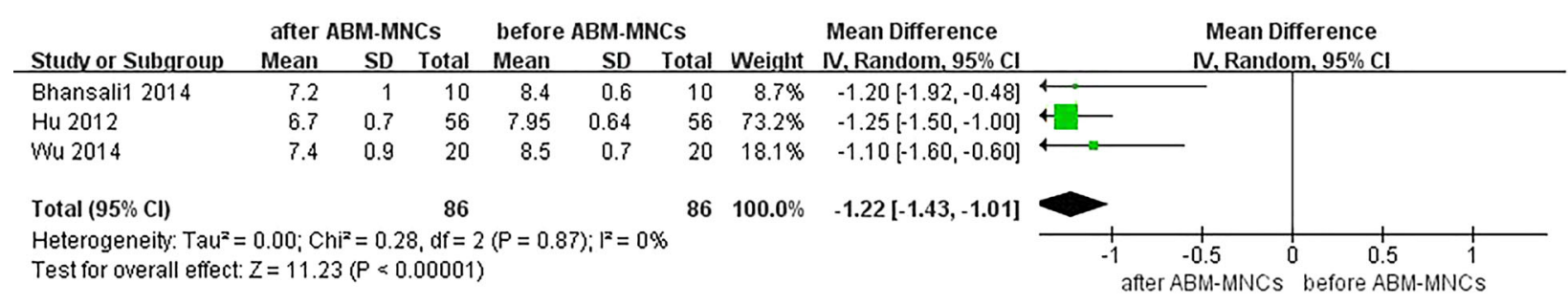

Fig. $3 \mathrm{HbA1c}$ changes before and after the ABM-MNC therapy after 12-month follow-up

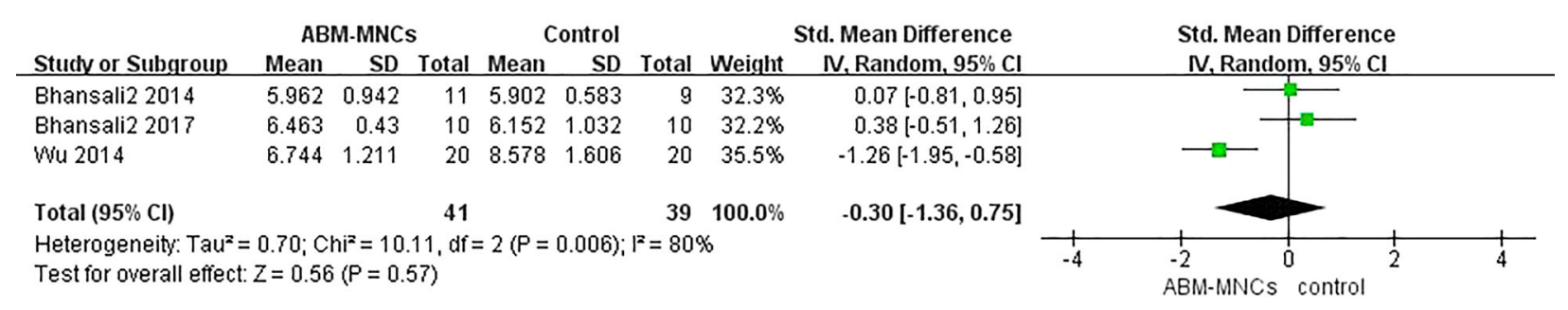

Fig. 4 FPG changes between the ABM-MNC therapy and control group

Table 2 Different stage comparison of FPG before and after ABM-MNC therapy

\begin{tabular}{|c|c|c|c|c|c|c|c|}
\hline \multirow[t]{2}{*}{ Items (months) } & \multicolumn{2}{|c|}{ Test for heterogeneity } & \multirow[t]{2}{*}{ Analysis model } & \multicolumn{2}{|c|}{ Test for overall effect } & \multirow[t]{2}{*}{ WMD or SMD } & \multirow[t]{2}{*}{ 95\% CI } \\
\hline & $\overline{I^{2}(\%)}$ & $P$ & & $\bar{Z}$ & $P$ & & \\
\hline 3 & 0 & 0.99 & Fixed & 1.40 & 0.16 & 0.40 & $(-0.16,0.96)$ \\
\hline 6 & 59 & 0.06 & Random & 0.91 & 0.36 & 0.34 & $(-0.39,1.08)$ \\
\hline 9 & 97 & $<0.001$ & Random & 0.64 & 0.52 & -0.62 & $(-2.50,1.27)$ \\
\hline 12 & 96 & $<0.001$ & Random & 0.98 & 0.33 & -0.88 & $(-2.64,0.88)$ \\
\hline
\end{tabular}

$P<0.001$; Table 4), but not at the 3-month and 6-month follow-up, respectively (Table 4).

\section{Effects of Stem Cell Therapy on Hyperglycemic Clamps}

Only two studies $[13,14]$ investigated the hyperglycemic clamp, and we observed a substantial improvement in the second-phase
C-peptide level in the ABM-MNC group after 6-month follow-up (Table 5).

\section{Effects of Stem Cell Therapy on Insulin Requirement}

Five trials included information on the insulin requirement with 98 patients $[13-16,18]$. There was a statistically significant decrease between 


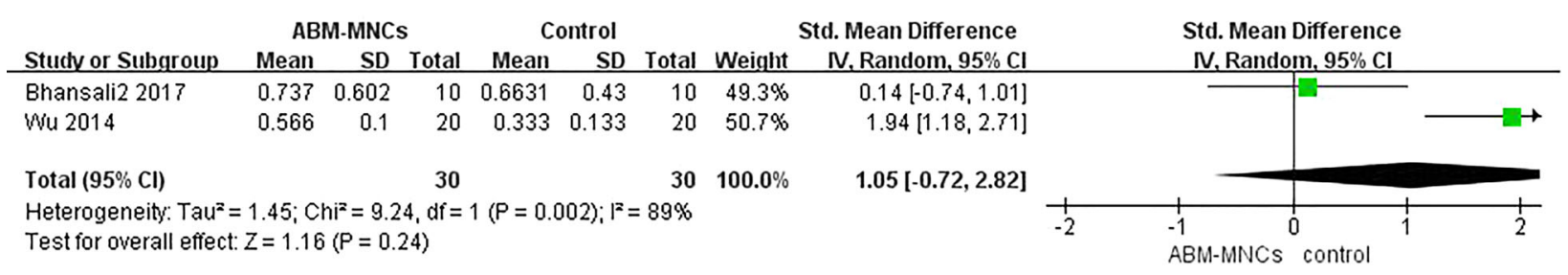

Fig. 5 Fasting C-peptide changes between the ABM-MNC therapy and control group

Table 3 Different stage comparison of fasting C-peptide before and after ABM-MNC therapy

\begin{tabular}{|c|c|c|c|c|c|c|c|}
\hline \multirow[t]{2}{*}{ Items (months) } & \multicolumn{2}{|c|}{ Test for heterogeneity } & \multirow[t]{2}{*}{ Analysis model } & \multicolumn{2}{|c|}{ Test for overall effect } & \multirow[t]{2}{*}{ WMD or SMD } & \multirow[t]{2}{*}{$95 \% \mathrm{CI}$} \\
\hline & $\overline{I^{2}(\%)}$ & $P$ & & $\bar{Z}$ & $P$ & & \\
\hline 3 & 0 & 0.87 & Fixed & 0.69 & 0.49 & -0.05 & $(-0.20,0.10)$ \\
\hline 6 & 0 & 1.00 & Fixed & 0.74 & 0.46 & -0.06 & $(-0.23,0.10)$ \\
\hline 12 & 56 & 0.13 & Random & 2.30 & 0.02 & 0.99 & $(0.15,1.84)$ \\
\hline
\end{tabular}

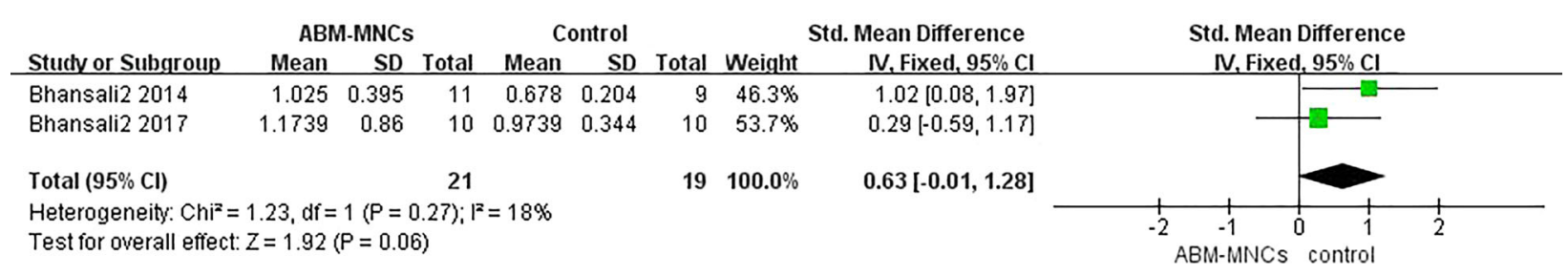

Fig. 6 Glucagon-stimulated changes in C-peptide level between the ABM-MNC therapy and control group

Table 4 Different stage comparison of glucagon-stimulated C-peptide levels before and after ABM-MNC therapy

\begin{tabular}{|c|c|c|c|c|c|c|c|}
\hline \multirow[t]{2}{*}{ Items (months) } & \multicolumn{2}{|c|}{ Test for heterogeneity } & \multirow[t]{2}{*}{ Analysis model } & \multicolumn{2}{|c|}{ Test for overall effect } & \multirow[t]{2}{*}{ WMD or SMD } & \multirow[t]{2}{*}{$95 \% \mathrm{CI}$} \\
\hline & $\overline{I^{2}(\%)}$ & $P$ & & $\bar{Z}$ & $P$ & & \\
\hline 3 & 0 & 0.97 & Fixed & 0.71 & 0.48 & -0.11 & $(-0.43,0.20)$ \\
\hline 6 & 46 & 0.14 & Fixed & 2.00 & 0.05 & 0.48 & $(0.01,0.95)$ \\
\hline 12 & 0 & 0.60 & Fixed & 3.36 & $<0.001$ & 0.91 & $(0.38,1.44)$ \\
\hline
\end{tabular}

the ABM-MNC group and control group after 12-month follow-up (MD, - 2.05; 95\% CI, -3.55 to $-0.55 ; P=0.008$; Fig. 7). Similarly, statistically significant decreases were observed in the insulin requirement after 3-, 6-, 9-, and 12-month follow-up in the ABM-MNC group, respectively (Table 6).

\section{Effects of Stem Cell Therapy on Insulin Resistance (HOMA-IR)}

Three studies examined the effects of stem cell therapy on HOMA-IR [13-15]. We did not find a statistically significant difference between the ABM-MNC group and control group after 12-month follow-up (MD, $-2.86 ; 95 \% \mathrm{CI}$, -9.76 to $4.03 ; P=0.42$; Fig. 8 ). No statistically significant differences were observed in HOMAIR after 3-, 6-, and 12-month follow-up in the ABM-MNC group, respectively, as well (Table 7).

\section{Effects of Stem Cell Therapy on Insulin Sensitivity (HOMA-S)}

Only two studies investigated HOMA-S as an outcome [13, 14]. No statistically significant 
Table 5 Different stage comparison of hyperinsulinemic clamp studies before and after ABM-MNC therapy after 6-month follow-up

\begin{tabular}{|c|c|c|c|c|c|c|c|}
\hline \multirow[t]{2}{*}{ Items } & \multicolumn{2}{|c|}{$\begin{array}{l}\text { Test for } \\
\text { heterogeneity }\end{array}$} & \multirow[t]{2}{*}{ Analysis model } & \multicolumn{2}{|c|}{$\begin{array}{l}\text { Test for overall } \\
\text { effect }\end{array}$} & \multirow[t]{2}{*}{ WMD or SMD } & \multirow[t]{2}{*}{$95 \% \mathrm{CI}$} \\
\hline & $\overline{I^{2}(\%)}$ & $P$ & & $\bar{Z}$ & $P$ & & \\
\hline Fasting C-peptide & 0 & 0.90 & Fixed & 0.61 & 0.54 & 0.61 & $(-1.37,2.60)$ \\
\hline AUC of 1st-phase C-peptide & 0 & 0.88 & Fixed & 0.23 & 0.82 & 0.03 & $(-0.20,0.25)$ \\
\hline AUC of 2nd-phase C-peptide & 0 & 0.92 & Fixed & 3.14 & 0.002 & 16.75 & $(6.28,27.21)$ \\
\hline
\end{tabular}

$A U C$ C-peptide area under the curve

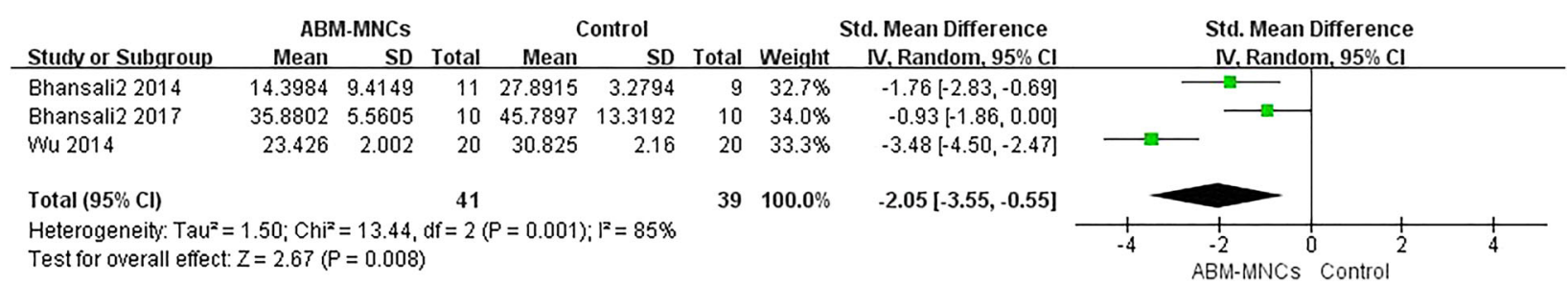

Fig. 7 Insulin requirement changes between the ABM-MNC therapy and control group

Table 6 Different stage comparison of the insulin requirement before and after ABM-MNC therapy

\begin{tabular}{|c|c|c|c|c|c|c|c|}
\hline \multirow[t]{2}{*}{ Items (months) } & \multicolumn{2}{|c|}{$\begin{array}{l}\text { Test for } \\
\text { heterogeneity }\end{array}$} & \multirow[t]{2}{*}{ Analysis model } & \multicolumn{2}{|c|}{$\begin{array}{l}\text { Test for overall } \\
\text { effect }\end{array}$} & \multirow[t]{2}{*}{ WMD or SMD } & \multirow[t]{2}{*}{$95 \% \mathrm{CI}$} \\
\hline & $\overline{I^{2}(\%)}$ & $P$ & & $\bar{Z}$ & $P$ & & \\
\hline 3 & 0 & 0.89 & Fixed & 3.36 & $<0.001$ & -32.09 & $(-50.77,-13.40)$ \\
\hline 6 & 0 & 0.78 & Fixed & 6.32 & $<0.001$ & -34.72 & $(-45.49,-23.96)$ \\
\hline 9 & 0 & 0.49 & Fixed & 5.66 & $<0.001$ & -39.27 & $(-52.87,-25.67)$ \\
\hline 12 & 89 & $<0.001$ & Random & 3.02 & 0.003 & -2.49 & $(-4.11,-0.87)$ \\
\hline
\end{tabular}

differences were observed in HOMA-S after 3-month and 6-month follow-up in the ABMMNC group (Table 8).

\section{Effects of Stem Cell Therapy on $\beta$-cell Function (HOMA- $\beta$ )}

Information on $\beta$-cell function was available in three trials [13-15]. Two studies showed that there was no significant difference between the ABM-MNC group and control group after 12-month follow-up (MD, - 7.18; 95\% CI, -37.48 to 23.12 ; $P=0.64$; Fig. 9). No statistically significant differences were observed in
HOMA- $\beta$ after 3-month, 6-month, and 12 -month follow-up in the ABM-MNC group (Table 9).

\section{Adverse Events}

Three studies investigated minor hypoglycemic episodes [13-15]. There was no statistically significant difference between the ABM-MNC group and control group after 12-month followup (two studies: MD, $0.49 ; 95 \% \mathrm{CI},-1.63$ to $2.61 ; P=0.65$; Fig. 10). However, a statistically significant increase was observed in hypoglycemic episodes after 3-month follow-up in 


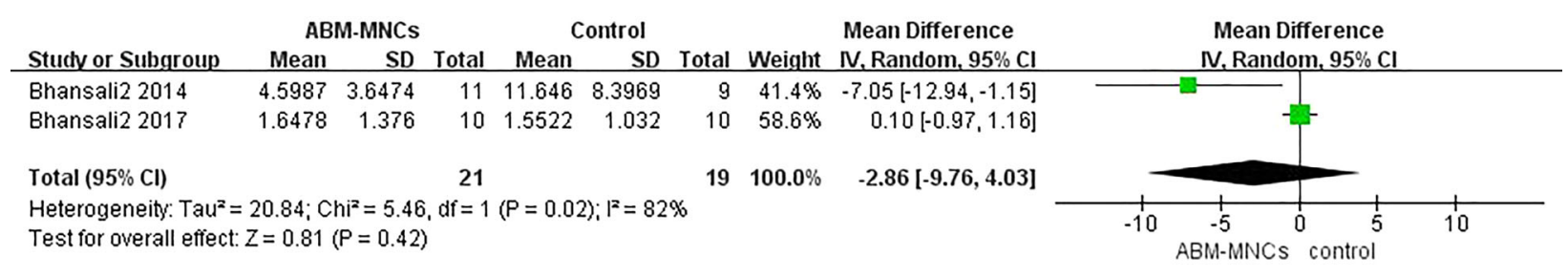

Fig. 8 HOMA-IR changes between the ABM-MNC therapy and control group

Table 7 Different stage comparison of HOMA-IR beore and after ABM-MNC therapy

\begin{tabular}{|c|c|c|c|c|c|c|c|}
\hline \multirow[t]{2}{*}{ Items (months) } & \multicolumn{2}{|c|}{ Test for heterogeneity } & \multirow[t]{2}{*}{ Analysis model } & \multicolumn{2}{|c|}{ Test for overall effect } & \multirow[t]{2}{*}{ WMD or SMD } & \multirow[t]{2}{*}{$95 \%$ CI } \\
\hline & $\overline{I^{2}(\%)}$ & $P$ & & $\bar{Z}$ & $P$ & & \\
\hline 3 & 0 & 0.84 & Fixed & 0.47 & 0.64 & -0.08 & $(-0.42,0.26)$ \\
\hline 6 & 0 & 0.44 & Fixed & 0.39 & 0.70 & -0.08 & $(-0.51,0.34)$ \\
\hline 12 & 0 & 0.67 & Fixed & 1.16 & 0.25 & 0.51 & $(-0.35,1.37)$ \\
\hline
\end{tabular}

Table 8 Different stage comparison of HOMA-S before and after ABM-MNC therapy

\begin{tabular}{|c|c|c|c|c|c|c|c|}
\hline \multirow[t]{2}{*}{ Items (months) } & \multicolumn{2}{|c|}{$\begin{array}{l}\text { Test for } \\
\text { heterogeneity }\end{array}$} & \multirow[t]{2}{*}{ Analysis model } & \multicolumn{2}{|c|}{$\begin{array}{l}\text { Test for overall } \\
\text { effect }\end{array}$} & \multirow[t]{2}{*}{ WMD or SMD } & \multirow[t]{2}{*}{$95 \% \mathrm{CI}$} \\
\hline & $\overline{I^{2}(\%)}$ & $P$ & & $\bar{Z}$ & $P$ & & \\
\hline 3 & 0 & 0.36 & Fixed & 0.49 & 0.62 & 9.75 & $(-28.96,48.47)$ \\
\hline 6 & 0 & 0.97 & Fixed & 0.75 & 0.46 & 14.82 & $(-24.12,53.77)$ \\
\hline
\end{tabular}

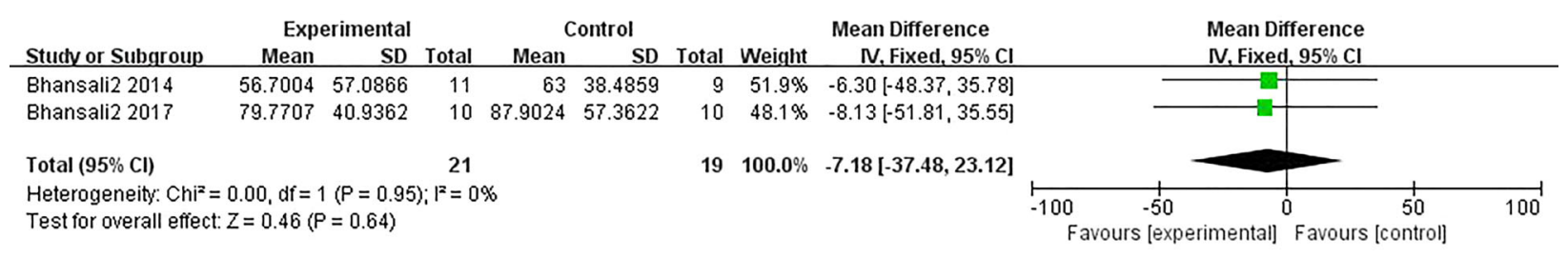

Fig. 9 HOMA- $\beta$ changes between the ABM-MNC therapy and control group

Table 9 Different stage comparison of HOMA- $\beta$ before and after ABM-MNC therapy

\begin{tabular}{|c|c|c|c|c|c|c|c|}
\hline \multirow[t]{2}{*}{ Items (months) } & \multicolumn{2}{|c|}{$\begin{array}{l}\text { Test for } \\
\text { heterogeneity }\end{array}$} & \multirow[t]{2}{*}{ Analysis model } & \multicolumn{2}{|c|}{$\begin{array}{l}\text { Test for overall } \\
\text { effect }\end{array}$} & \multirow[t]{2}{*}{ WMD or SMD } & \multirow[t]{2}{*}{$95 \% \mathrm{CI}$} \\
\hline & $\overline{I^{2}(\%)}$ & $P$ & & $\bar{Z}$ & $P$ & & \\
\hline 3 & 0 & 0.37 & Fixed & 0.22 & 0.83 & -2.26 & $(-22.71,18.19)$ \\
\hline 6 & 0 & 0.53 & Fixed & 0.22 & 0.83 & -1.87 & $(-18.83,15.10)$ \\
\hline 12 & 0 & 0.85 & Fixed & 1.68 & 0.09 & 21.34 & $(-3.5,46.19)$ \\
\hline
\end{tabular}




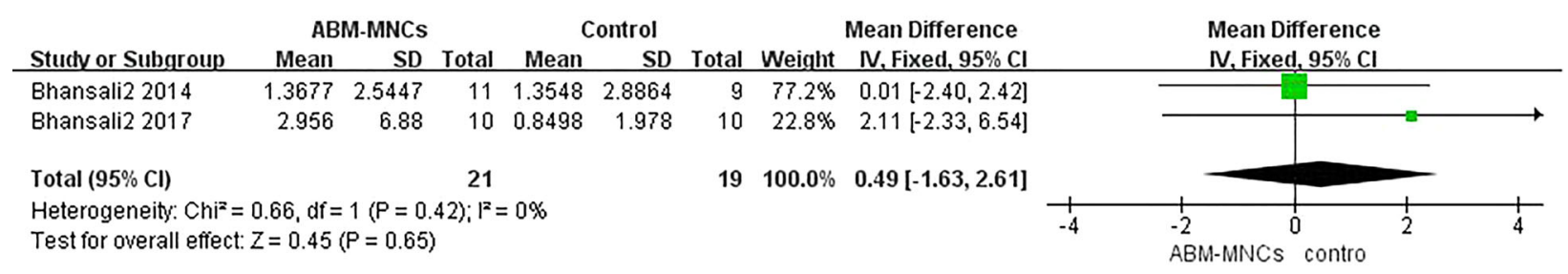

Fig. 10 Hypoglycemic episode changes between the ABM-MNC therapy and control group

Table 10 Different stage comparison of hypoglycemic episodes before and after ABM-MNC therapy

\begin{tabular}{|c|c|c|c|c|c|c|c|}
\hline \multirow[t]{2}{*}{ Items (months) } & \multicolumn{2}{|c|}{ Test for heterogeneity } & \multirow[t]{2}{*}{ Analysis model } & \multicolumn{2}{|c|}{ Test for overall effect } & \multirow[t]{2}{*}{ WMD or SMD } & \multirow[t]{2}{*}{$95 \% \mathrm{CI}$} \\
\hline & $\overline{I^{2}(\%)}$ & $P$ & & $\bar{Z}$ & $P$ & & \\
\hline 3 & 0 & 0.34 & Fixed & 3.70 & $<0.001$ & 6.40 & $(3.01,9.79)$ \\
\hline 6 & 0 & 0.96 & Fixed & 0.30 & 0.76 & -0.30 & $(-2.25,1.65)$ \\
\hline 12 & 7 & 0.30 & Fixed & 0.75 & 0.45 & -1.00 & $(-3.61,1.62)$ \\
\hline
\end{tabular}

the ABM-MNC group (Table 10). Nevertheless, no major hypoglycemia was observed. Only seven patients (3.2\%) reported mild adverse effects of abdominal pain ( 2 patients), nausea (3 patients), arterial puncture-site hemorrhage (1 patient), and local extravasation of blood (1 patient). No serious chronic side effects or lingering effects appeared during the follow-up, which indicated the ABM-MNC therapy was relatively safe for T2DM treatment.

\section{DISCUSSION}

Our meta-analysis of six studies with 114 patients suggested that, compared with control therapy, the HbA1c level decreased significantly in the ABM-MNC therapy group after a 12-month follow-up. In addition, the level of HbA1c before and after ABM-MNC therapy showed a significant decrease after a 12-month follow-up. However, ABM-MNC therapy has no statistically significant effect on the FPG, fasting C-peptide level, HOMA-IR level, HOMA- $\beta$ level, or insulin sensitivity.

Stem cells are a potential source of insulinproducing cells due to the capacity for proliferation and differentiation [19]. Evidence has shown that the trans-differentiation of stem cells into insulin-producing cells and infused stem cells could lead to differentiation of local progenitor cells and inflammation in the pancreas in murine models $[3,20]$. Bone marrow gives rise to hematopoietic stem cells, endothelial progenitor cells (EPCs), and mesenchymal stem cells (MSCs) [21]. Implantation of bone marrow-derived stem cells could repair and regenerate tissues. In addition, autologous bone marrow implantation could avoid immune rejection and ethical issues [22]. Based on the previously mentioned advantages, autologous bone marrow stem cells have been considered an important substitute source of $\beta$-cells. In fact, stem cell treatment has shown inspiring outcomes in terms of restoring islet function and improving diabetic control in diabetic animal models [4]. However, limited evidence has examined the utility of ABM-MNC transplantation for the treatment of T2DM in humans. This meta-analysis aims to assess the safety and efficacy of ABM-MNC transplantation for T2DM based on all available evidence.

Our findings showed no significant differences of FPG at the end of the follow-up in the included trials, which is inconsistent with the previous meta-analysis [7]. However, this metaanalysis included Chinese studies published in Chinese, and this study did not assess the quality of the studies included. Furthermore, the quality of some of the included studies was 
not well controlled, and some studies were not randomized. In addition, some of the studies had small sample sizes, which could introduce bias. In the present meta-analysis of RCTs, we only included studies published in English and with high-quality study designs.

Our results also showed a significant increase in fasting C-peptide and glucagon-stimulated C-peptide after 12-month follow-up in the ABM-MNC therapy group. Unexpectedly, there was no significant alteration in HOMA- $\beta$ level between the ABM-MNC therapy group and control group or different stages after ABMMNC therapy. One of the potential explanations is the small sample size of the trials and small number of cases, which may lead to insufficient statistical power. However, we observed ABM-MNC therapy was associated with an augmented C-peptide response on clamp study, and this was further demonstrated by a significant increase in the glucagon-stimulated C-peptide response.

The level of the insulin requirement showed a significant decrease after 3-, 6-, 9-, and 12-month follow-up in the ABM-MNC therapy group. Furthermore, the insulin requirement in the ABM-MNC therapy group was significantly reduced compared with the control group after a 12-month follow-up. Bhansali et al. [13] also demonstrated that ABM-MNC therapy could reduce the exogenous insulin requirement by $\geq 50 \%$ and maintain $\mathrm{HbA} 1 \mathrm{c}<7.0 \%$ among the $70 \%$ of patients with T2DM. Notably, only $3.2 \%$ of patients receiving ABM-MNCs for T2DM experienced adverse events. No serious adverse events were noted, and no significant hypoglycemia was observed in all six studies. Hence, $\mathrm{ABM}-\mathrm{MNC}$ transplantation is considered a safe therapy for T2DM.

The potential mechanism underlying the impact of ABM-MNCs on diabetes was not fully elucidated. In the present study, we found a decrease in the insulin requirement. Our results suggested the possibility that ABM-MNCs are mainly involved in improving insulin sensitivity [23]. Another potential mechanism is that ABM-MNCs are associated with the maintenance of $ß$-cells, which could prevent islet cell loss [24].
To the best of our knowledge, this metaanalysis is the most comprehensive and update evaluation of the safety and efficacy of ABMMNCs in T2DM to date. However, several limitations merit consideration. First, we included some trials with relatively small sample sizes, which may have insufficient power to address the research question. Second, the numbers of stem cells in the six included studies varied. Different investigators used variable doses of stem cells in the clinical studies, and it was shown that the response was greater with a higher dose $[25,26]$. However, due to the limitation of the small numbers of studies, we were unable to do the subgroup analysis according to the doses or dose-response analysis. Third, the follow-up time was not adequately long. These patients should remain under close surveillance for the development of any neoplasia, as stem cells, being multi-potent, have the potential for malignant transformation. Finally, we may not have identified the unpublished articles and trials that were not reported in English. We assumed that most of the well-designed trials would have been published in English-language journals. However, our comprehensive literature search and the results of non-publication bias showed that our meta-analysis was not driven by selective publication of positive findings.

\section{CONCLUSION}

ABM-MNCs could improve glycemic control among patients with diabetes and could be used safely and efficiently to treat patients with T2DM in the short term; however, the longterm effects warrant more trials with larger sample sizes and longer follow-ups.

\section{ACKNOWLEDGEMENTS}

Funding. This study, including the article processing charges, is funded by the Innovation Fund for Outstanding Talents of Henan Puyan: 100,308 . 
Authorship. All authors meet the criteria of the International Committee of Medical Journal Editors (ICMJE) for authorship of this article, take responsibility for the integrity of the work as a whole. and have given their approval for this version to be published.

Disclosures. Xue-Jun Guo, Feng-Ju Li, YuZhuo He, Shu-Fang Hou, Hong-Bin Zhu, Ying Cheng, Zhen Nan, and Xiao-Yan Lin have nothing to disclose.

Compliance with Ethics Guidelines. This article is based on previously conducted studies and does not contain any studies with human participants or animals performed by any of the authors.

Data Availability. The data sets generated and/or analyzed during the current study are available from the corresponding author on reasonable request.

Open Access. This article is distributed under the terms of the Creative Commons Attribution-NonCommercial 4.0 International License (http://creativecommons.org/licenses/ by-nc/4.0/), which permits any noncommercial use, distribution, and reproduction in any medium, provided you give appropriate credit to the original author(s) and the source, provide a link to the Creative Commons license, and indicate if changes were made.

\section{REFERENCES}

1. Bennett PH. Diabetes mortality in the USA: winning the battle but not the war? Lancet. 2018;391(10138):2392-3 (London, England).

2. Tuomi T. Type 1 and type 2 diabetes: what do they have in common? Diabetes. 2005;54(Suppl 2):S40-5.

3. Estrada EJ, Valacchi F, Nicora E, Brieva S, Esteve C, Echevarria L, Froud T, Bernetti K, Cayetano SM, Velazquez O, Alejandro R, Ricordi C. Combined treatment of intrapancreatic autologous bone marrow stem cells and hyperbaric oxygen in type 2 diabetes mellitus. Cell Transplant. 2008;17(12):1295-304.
4. Zhang YH, Wang HF, Liu W, Wei B, Bing LJ, Gao YM. Insulin-producing cells derived from rat bone marrow and their autologous transplantation in the duodenal wall for treating diabetes. Anat Rec. 2009;292(5):728-35 (Hoboken, NJ: 2007).

5. Bhansali A, Upreti V, Khandelwal N, Marwaha N, Gupta V, Sachdeva N, Sharma RR, Saluja K, Dutta P, Walia R, Minz R, Bhadada S, Das S, Ramakrishnan S. Efficacy of autologous bone marrow-derived stem cell transplantation in patients with type 2 diabetes mellitus. Stem Cells Dev. 2009;18(10):1407-16.

6. El-Badawy A, El-Badri N. Clinical efficacy of stem cell therapy for diabetes mellitus: a meta-analysis. PLoS One. 2016;11(4):e0151938.

7. Wang ZX, Cao JX, Li D, Zhang XY, Liu JL, Li JL, Wang M, Liu Y, Xu BL, Wang HB. Clinical efficacy of autologous stem cell transplantation for the treatment of patients with type 2 diabetes mellitus: a meta-analysis. Cytotherapy. 2015;17(7):956-68.

8. Moher D, Liberati A, Tetzlaff J, Altman DG. Preferred reporting items for systematic reviews and meta-analyses: the PRISMA statement. Int J Surg. 2010;8(5):336-41.

9. Page MJ, McKenzie JE, Kirkham J, Dwan K, Kramer S, Green S, Forbes A. Bias due to selective inclusion and reporting of outcomes and analyses in systematic reviews of randomised trials of healthcare interventions. Cochrane Database Syst Rev. 2014 (10):Mr000035.

10. Wan X, Wang W, Liu J, Tong T. Estimating the sample mean and standard deviation from the sample size, median, range and/or interquartile range. BMC Med Res Methodol. 2014;14:135.

11. Luo D, Wan X, Liu J, Tong T. Optimally estimating the sample mean from the sample size, median, mid-range, and/or mid-quartile range. Stat Methods Med Res. 2018;27(6):1785-805.

12. DerSimonian R, Laird N. Meta-analysis in clinical trials revisited. Contemp Clin Trials. 2015;45(Pt A):139-45.

13. Bhansali S, Dutta P, Kumar V, Yadav MK, Jain A, Mudaliar S, Bhansali S, Sharma RR, Jha V, Marwaha N, Khandelwal N, Srinivasan A, Sachdeva N, Hawkins M, Bhansali A. Efficacy of autologous bone marrow-derived mesenchymal stem cell and mononuclear cell transplantation in type 2 diabetes mellitus: a randomized, placebo-controlled comparative study. Stem Cells Dev. 2017;26(7):471-81.

14. Bhansali S, Dutta P, Yadav MK, Jain A, Mudaliar S, Hawkins M, Kurpad AV, Pahwa D, Yadav AK, Sharma RR, Jha V, Marwaha N, Bhansali S, Bhansali A. Autologous bone marrow-derived mononuclear 
cells transplantation in type 2 diabetes mellitus: effect on beta-cell function and insulin sensitivity. Diabetol Metab Syndr. 2017;9:50.

15. Bhansali A, Asokumar P, Walia R, Bhansali S, Gupta V, Jain A, Sachdeva N, Sharma RR, Marwaha N, Khandelwal N. Efficacy and safety of autologous bone marrow-derived stem cell transplantation in patients with type 2 diabetes mellitus: a randomized placebo-controlled study. Cell Transplant. 2014;23(9):1075-85.

16. Wu Z, Cai J, Chen J, Huang L, Wu W, Luo F, Wu C, Liao L, Tan J. Autologous bone marrow mononuclear cell infusion and hyperbaric oxygen therapy in type 2 diabetes mellitus: an open-label, randomized controlled clinical trial. Cytotherapy. 2014;16(2):258-65.

17. Hu J, Li C, Wang L, Zhang X, Zhang M, Gao H, Yu $\mathrm{X}$, Wang F, Zhao W, Yan S, Wang Y. Long term effects of the implantation of autologous bone marrow mononuclear cells for type 2 diabetes mellitus. Endocr J. 2012;59(11):1031-9.

18. Bhansali A, Upreti V, Walia R, Gupta V, Bhansali S, Sharma RR, Grover S, Marwaha N, Khandelwal N. Efficacy and safety of autologous bone marrow derived hematopoietic stem cell transplantation in patients with type 2 DM: a 15 months follow-up study. Indian J Endocrinol Metab. 2014;18(6): 838-45.

19. Banerjee I, Sharma N, Yarmush M. Impact of coculture on pancreatic differentiation of embryonic stem cells. J Tissue Eng Regen Med. 2011;5(4): 313-23.
20. Dong QY, Chen L, Gao GQ, Wang L, Song J, Chen B, Xu YX, Sun L. Allogeneic diabetic mesenchymal stem cells transplantation in streptozotocin-induced diabetic rat. Clin Invest Med. 2008;31(6):E328-37.

21. Goligorsky MS, Salven P. Concise review: endothelial stem and progenitor cells and their habitats. Stem Cells Transl Med. 2013;2(7):499-504.

22. Fotino C, Ricordi C, Lauriola V, Alejandro R, Pileggi A. Bone marrow-derived stem cell transplantation for the treatment of insulin-dependent diabetes. Rev Diabet Stud RDS. 2010;7(2):144-57.

23. Baraniak PR, McDevitt TC. Stem cell paracrine actions and tissue regeneration. Regen Med. 2010;5(1):121-43.

24. Wang L, Zhao S, Mao H, Zhou L, Wang ZJ, Wang HX. Autologous bone marrow stem cell transplantation for the treatment of type 2 diabetes mellitus. Chin Med J. 2011;124(22):3622-8.

25. Skyler JS, Fonseca VA, Segal KR, Rosenstock J. Allogeneic mesenchymal precursor cells in type 2 diabetes: a randomized, placebo-controlled, doseescalation safety and tolerability pilot study. Diabetes Care. 2015;38(9):1742-9.

26. Mudrabettu C, Kumar V, Rakha A, Yadav AK, Ramachandran R, Kanwar DB, Nada R, Minz M, Sakhuja V, Marwaha N, Jha V. Safety and efficacy of autologous mesenchymal stromal cells transplantation in patients undergoing living donor kidney transplantation: a pilot study. Nephrology. 2015;20(1):25-33 (Carlton, Vic). 